\title{
The Value of Bellini's Art Songs in Vocal Music Training
}

\author{
Qinwen Yang \\ College of Arts and Design \\ Yunnan University \\ Kunming, China
}

\begin{abstract}
Bellini's song creation emphasizes singing nature; vocal characteristics which accord with singing psychology and vocal performance are very suitable for training and developing the technical ability of singing. In European and American countries, Bellini's opera arias and art songs have long been regarded as the classic textbook for "Bel Canto". Bellini's art songs cover a variety of technical skills for singing and are able to fully improve their singing skills through continuous practice. Bellini's art songs not only can help to establish a good singing mental state and establish a smooth and stable singing channel; they can also consolidate the mid-range area and develop highpitched sound areas, and at the same time training the breath use ability in singing practice; it can also enable singers to develop and practice smooth, coherent, rounded, soft, dexterous and other singing techniques, also they can improve the rapid sentence singing and other coloratura skills, as well as to cultivate the delicate, profound internal expression of emotional singing.
\end{abstract}

Keywords—Bellini; art songs; vocal training; value

\section{INTRODUCTION}

Bellini is very versed in Bel Canto singing technique. His song creation pays more attention to the vocal characteristics of singing psychology and singer function, which is very suitable for training and developing the technical ability of singing voice. In the second "Golden Age of Bel Canto" of the first half of 19th century, his songwriting influenced the further development of the technical skills of Bel Canto at the time and contributed to the prosperity of traditional Italian Bel Canto.

The 20th century world-famous coloratura soprano Sutherland once benefited a lot from singing Bellini's operatic works, and she believed from her experience that Bellini's opera arias and art songs has helped her solve the vocal technical problem of unnatural and unsteady low pitch. So, in European and American countries, Bellini's opera arias and art songs have long been regarded as the classic textbooks for "Bel Canto".

Therefore, the study of Bellini's art songs aims to help more vocal singers or enthusiasts to effectively develop their voice art abilities and improve their artistic accomplishments, which has a significant value for better mastering the various techniques of Western Bel Canto singing.

\section{A. Bellini's Art Songs Help Establish Good Singing Mental State}

First of all, the melody of Bellini's art songs is very beautiful and lyrical, with melodic lines coherent, ups and downs, romantic, etc. This kind of melodic character has a very good singing nature. The beautiful lyrical and romantic melody is very contagious. It can really make people reluctant and quiet in the mood of the song. So singers are often willing to learn and sing it. A beautiful singing desire can arouse the learner or singer's singing spirit, and can help establish a good singing mental state: an excited, focused, and agitated mood that promotes the relaxation of the singing vocalization function in order to better develop and practice singing ability.

Second, the melody of Bellini's art songs used many same degree interval, progressive interval, and smooth and soothing melody. The use of such melody makes the singer has a kind of stability, harmony, steady, comfort, and tranquility psychological feelings while singing. He or she can sing in a very relaxed, comfortable and focused state. Such a state can make the singing breathe even and deep, and it can help establish a good singing breathing basis while establishing a good singing mental state.

In addition, Bellini's best-used triple rhythm is a rhythmic rhythm that makes the melody of the song smooth, coherent, and mellow, allowing the singer to feel a relaxed, pleasant, and relaxing atmosphere. In the meanwhile bring a light, agile and lively infectivity, so that the singing mental state is natural, relax, calm and ease, and the singing breathe is also even, smooth and deep. It laid a good foundation for establishing a good singing vocal state.

Also, Bellini's art songs have a not so wide range of sounds, written in the middle of the vocal area, close to the speaking voice zone, without a high pitched treble or low bass. Such singing area is natural and not exaggerated. It also makes the singing experience more relaxing and enjoyable, without feeling difficult, frightening and tense. This is also a good singing mental state.

After long-term training and consolidating good singing mental state and forming a fixed posture and habits, when continuously training and developing difficult technical techniques such as high-vocal areas, singing mental feeling 
will naturally relax, no longer feel afraid and nervous. The concert became calm and easy.

\section{B. Bellini's Art Songs Can Consolidate ad Develop Singing Skills}

Bellini himself has a lot of research on Bel Canto singing, and he is also very familiar with vocal music skills. Therefore, his vocal works accord with the requirements of vocal singing: singing nature, lyricism, coherence, dexterity, fluency, rich and delicate emotionality and so on. These characteristics are very beneficial and advantageous for consolidating and developing singing skills. In accordance with the requirements of vocal singing, it is mainly reflected in the melody of Bellini's songs. The characteristics of his melody creation are very valuable for vocal training.

In Bellini's art songs, its melody writing includes the progression interval, jump interval, same degree interval, octave interval, arpeggio, ascending scale melody, descending scale melody, and ascending-descending scale combination melody. These are similar to the content of our daily vocal etudes. Our daily vocal etudes also use these intervals and melodies to help training singing.

In addition, in his art songs, the consistent and undulating long sentences, the rapid coloratura sentences, and the long tail singing are the content of difficulty training in further developing singing techniques.

Therefore, Bellini's art songs contain very comprehensive singing skills. They can be used as daily vocal training etude, and also they are the classic textbooks that could help singers fully training their vocal techniques.

\section{THE Following ARE THE DETAILED ANALYSIS FOR THE VALUE OF BELLINI'S ART SONGS ON VOCAL TRAINING:}

\section{A. Same Degree Interval Training}

There are many melody of the same degree interval in Bellini's art songs. The melody of the same degree interval has a good training effect on the oral status keeping while singing. Because the lyrics are different, so the vocal head and end are also different, so that the vocalized oral state is easily changed, and the sound position and timbre are not uniform, so use the same degree interval, which is the same pitch to maintain and stabilize the vocal state of the mouth is very necessary and beneficial. At the same time, it is also very beneficial to maintain the breathing state of singing, making the singing breath smooth, even and long-lasting. Here are some examples of the same degree interval melody in Bellini's art songs:

Spectral example No.14 "Fenesta ch lucive"

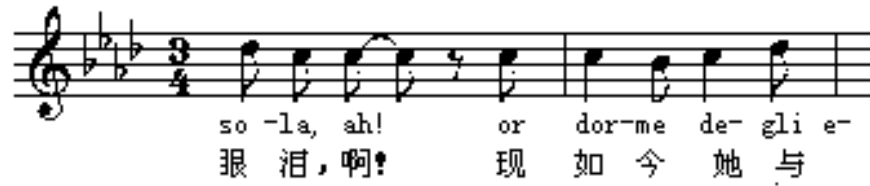

Spectral example No. 15 "O crudel che il mio pianto"

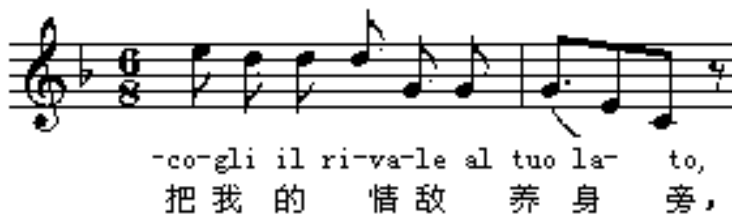

Spectral example No.16 "Quando incise su quel marmo"

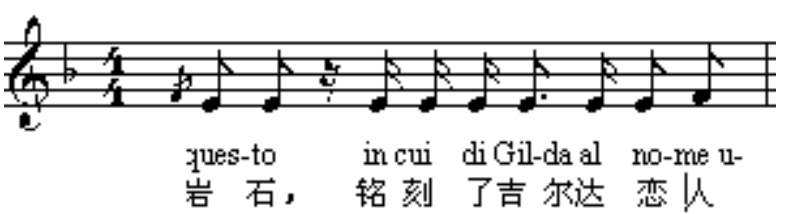

\section{B. Second and Third Degree Interval Training}

In Bellini's art songs, the use of second and third-tone melody is very wide. This melody makes the melody lines appear smoother and more soothing, and the speech-like tone is natural, simple, and unpretentious, which make people's mental state also relaxed, comfortable and pleasant. Such a musical melody can be used as a cornerstone for stabilizing singing vocal states, adjusting singing respiration, and developing singing techniques. It gradually and progressively develops melody in fourth-tone intervals, fifth-tone intervals, and even big jump interval melody like octaves. In other words, it is an important foundation for the development of all singing training.

Spectral example No.17 "Vaga luna che inargenti"

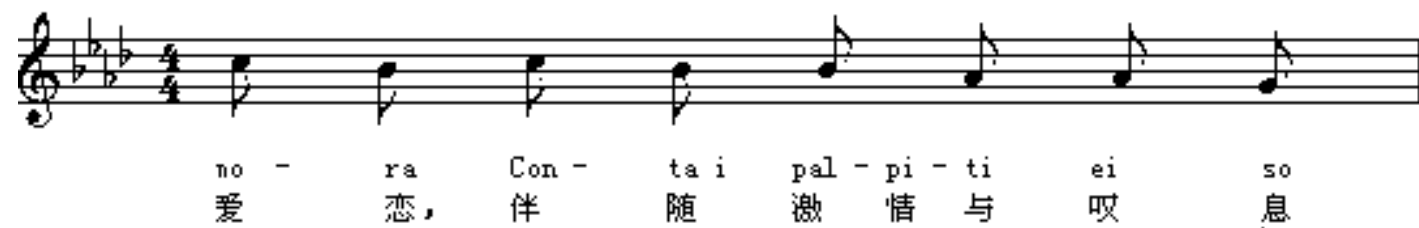


Spectral example No.18 "L'abbadono"
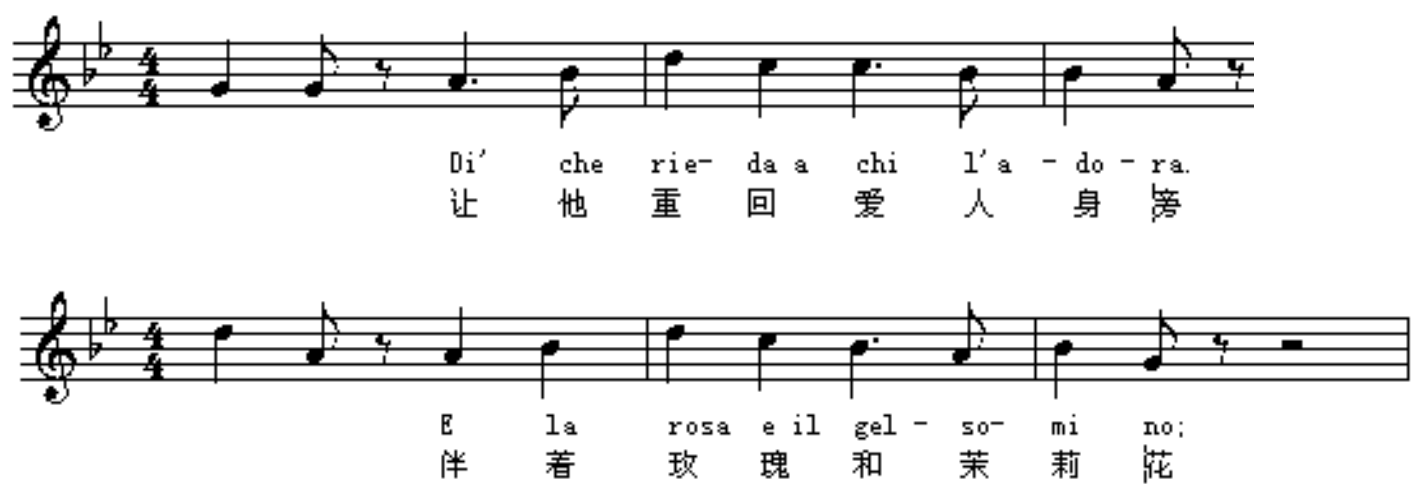

\section{Scale Melody Training}

Scale melody is used very frequently in Bellini's art songs, including ascending scale melody, descending scale melody, and ascending-descending scale melody. This is a continuous link between the second and third degrees. The melody is smooth, but the melody lines become undulating and continuous. The scale melody is developed on the basis of the second and third degree melody. Through training and consolidating the second and third degree melody for a certain period of time, it is easier to gradually enter the scale melody training.

1) Ascending scale melody training: Ascending scale melody has a positive and exciting psychological feeling. As the pitch rises, it promotes the adjustment of oral state for Spectral example No.19 "Fenesta ch lucive" active vocalization. It also promotes the breathing function of the singing, especially the state of the diaphragm can be supported and maintained. Exercise will also help to adjust the uniform use of singing and breathing.

This ascending scale melody starts with a relatively low tone and gradually rises to a relatively high tone. In this way, inhaling at the low pitch, it will be easier to get deep breathing support, as the pitch increase evenly and steadily, the amount of breath is also increasing, until finished at the end of the relatively high tail tone, which trained the deep and full inhale of the air and the uniform and control of exhalation. In addition, the smooth progression of ascending scale melody can help stabilize and maintain the ability to sing with the inhaled state.

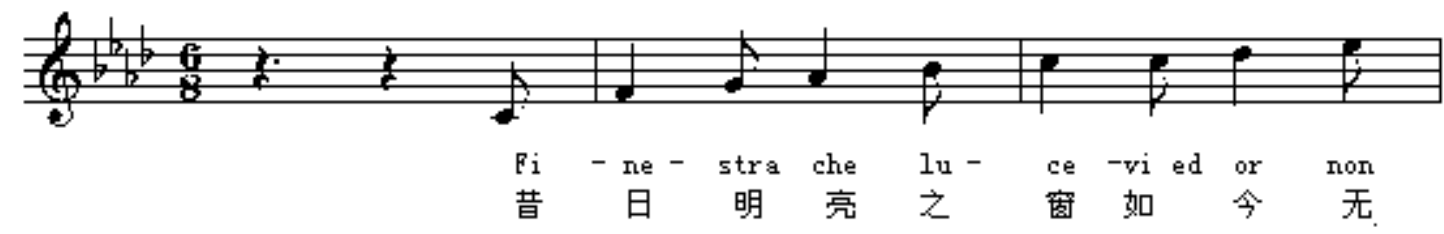

Spectral example No. 20 "Torna, vezzosa Fillide"

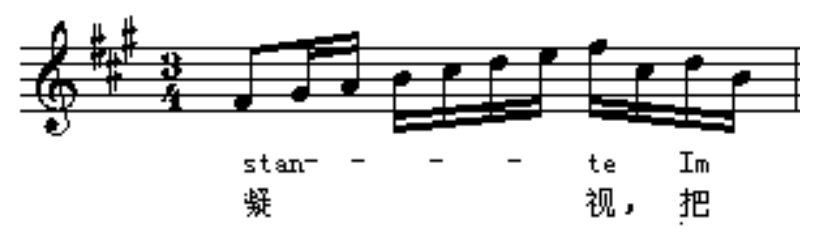

Spectral example No.21 "Seilmiononesapervoibranate"

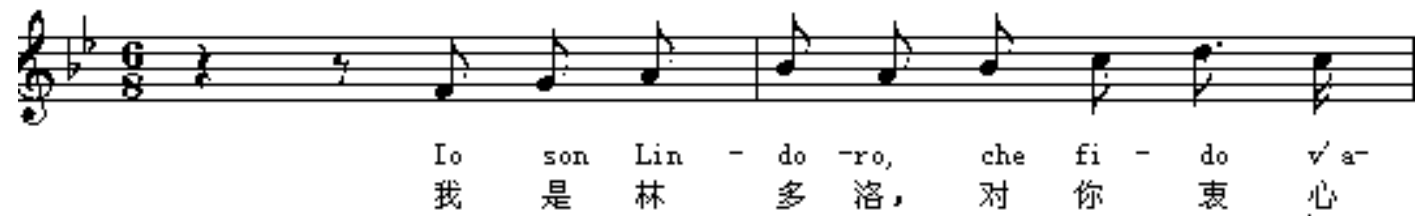


Spectral example No.22 "Vaga luna che inargenti"

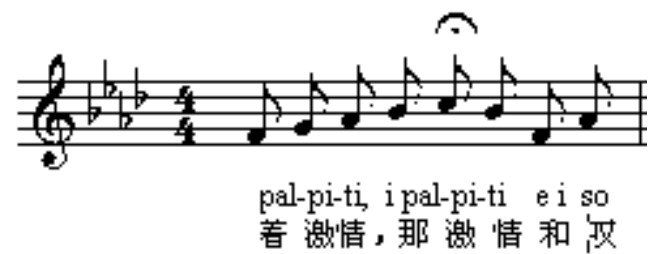

2) Descending scale melodytraining

The descending scale melodystarts from relatively high tone to relatively low tone smooth and balance. However, the first tone is a relatively high tone, and the singer will inevitably experience some nervous state of mind. Such exercises need to be trained on the basis of a steady state of mind and vocal vocalization after a certain period of time in the same interval and the second and third intervals training.

The practice of descending scale melody plays a key role in the inhalation of the first tone. Because when the first tone is relatively high, the singer will naturally and aggressively inhale so that he can breathe enough air to support the high

Spectral example No.23 "L'abbadono" tone signing. But this method is wrong, the breath is very low, not enough, so that there is a state of crowding and blocking. In addition, the singers' psychological state is also more intense and does not relax. Therefore, the descending scale melody practice mainly emphasizes the smoothness and naturalness of the inhalation state.

In addition, the descending scale melody gives the singer a sighing, returning psychological feeling, but also a melancholy, sad psychological experience. This feeling can make people to relieve stress with sigh and cry. And we often say that while sing, in order to make the breath deep and at low position, it always stay at the diaphragm position, so normally singing with a sigh or cry state. Such a deep breath and a deep inhalation state will keep well. So the mental state and singing functions will be very relaxed, and the singing channel will be open and natural. The sound produced in this state is round, thick, smooth, natural, and soft.

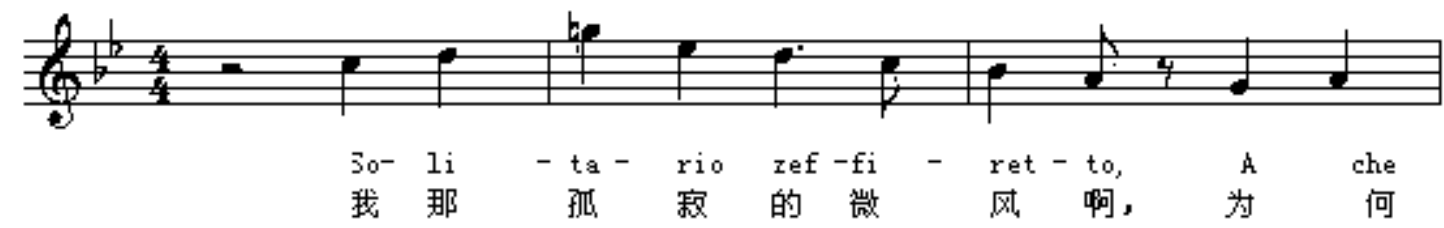

Spectral example No. 24 "O crudel che il mio pianto"

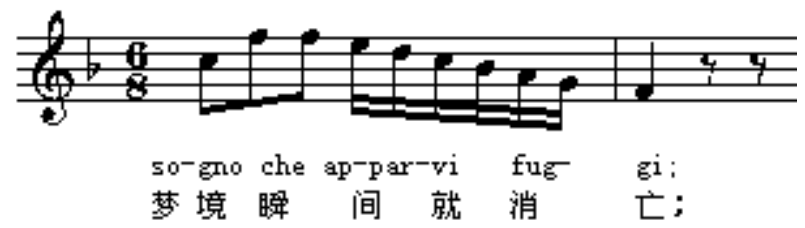

Spectral example No.25 "Torna, vezzosa Fillide"

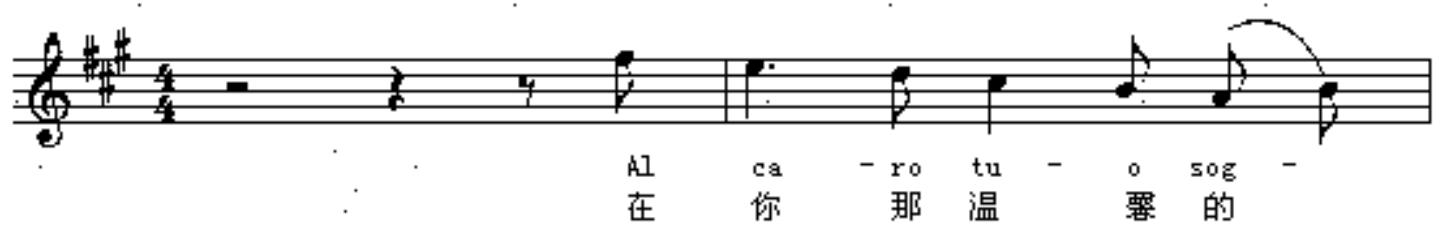

Spectral example No.26 "Bella Niceche damore"

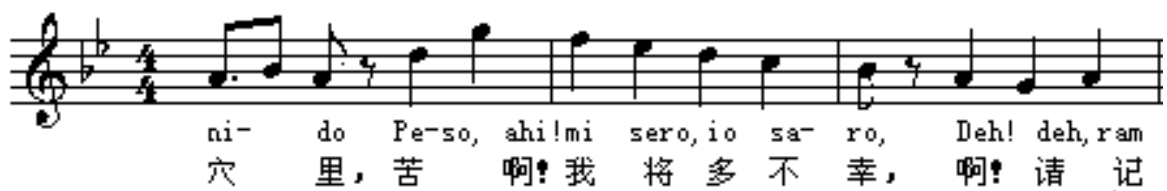


Spectral example No.27 "Malinconianinfa gentile"

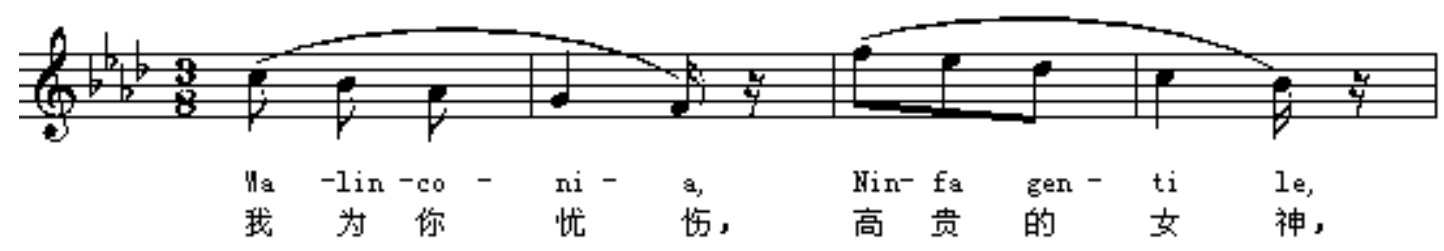

3) Ascending-descending scale melody training

Ascending-descending scale melody gradually increases from a relatively low tone to a relatively high tone, and then returns to a relatively low tone, forming an arched line, as the Bellini style vocal lyrical melody which mentioned in the Spectral example No.28 "L'allegronarinaro" previous chapter. Due to the reason of second intervals, this arched melody is more soothing, smoother, more balanced, and symmetrical. It can balance the vocal state and the state of mind, which has a very good training value for the adjustment of the use of singing breathes, and the oral state of singing.

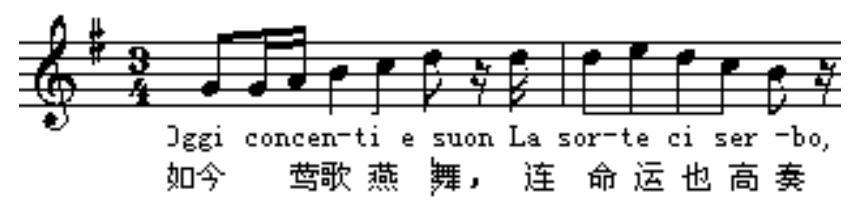

Spectral example No.29 "Ma rendi pur contrnto"

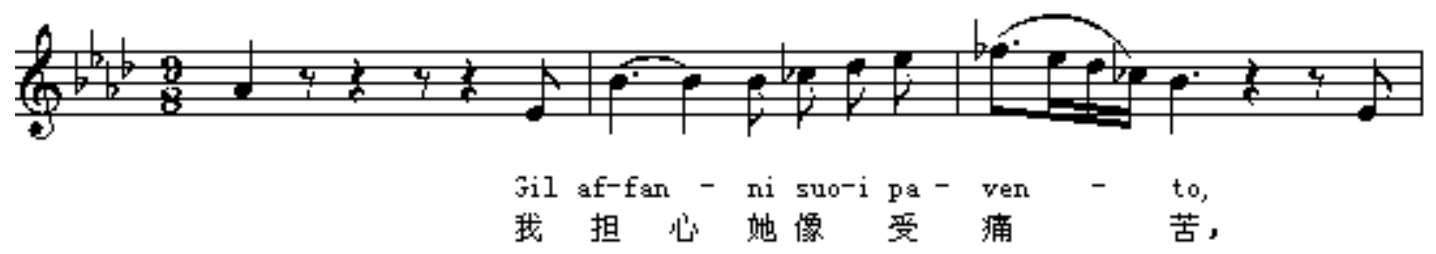

Spectral example No.30 "A palpitar daffanno"

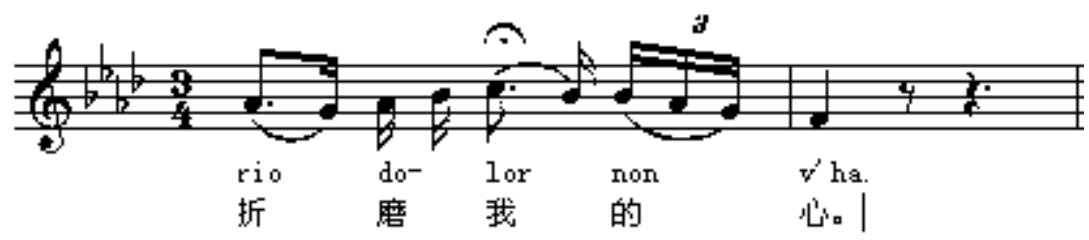

Spectral example No.31 "Vaga luna che inargenti"

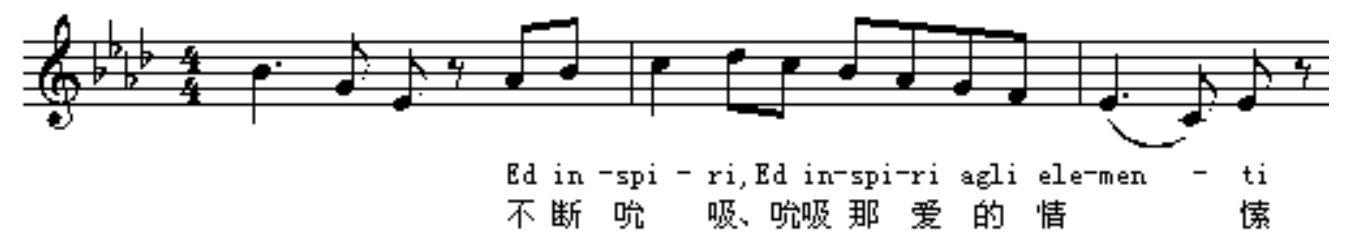

Spectral example No.32 "Per pieta bellidol mio"

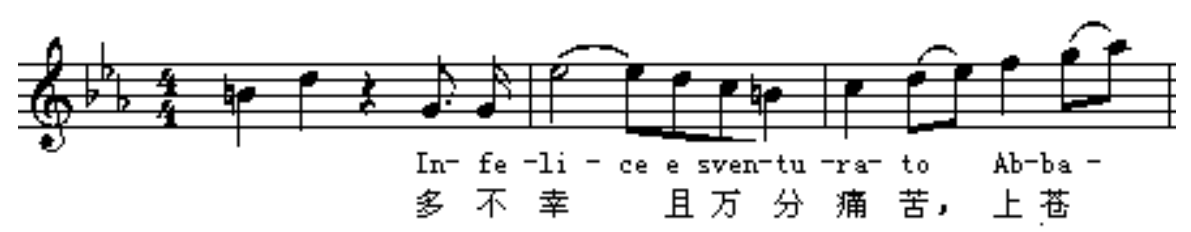




\section{Arpeggio Training}

There are many arpeggio melodies in Bellini's art songs, which is also the indispensable vocal practice in singer's daily training. The arpeggio practice can be said to be a melody training in which the third or fourth degree intervals are continuously connected. It is a practice based on the training of the second and third degree intervals and the difficulty is increased. As long as under the vocalization state of the second and third degree scale practice, it is not difficult to grasp the slightest adjustment of the amount of breath and the endurance of breathing.

Spectral example No.33 "Torna, vezzosa Fillide"

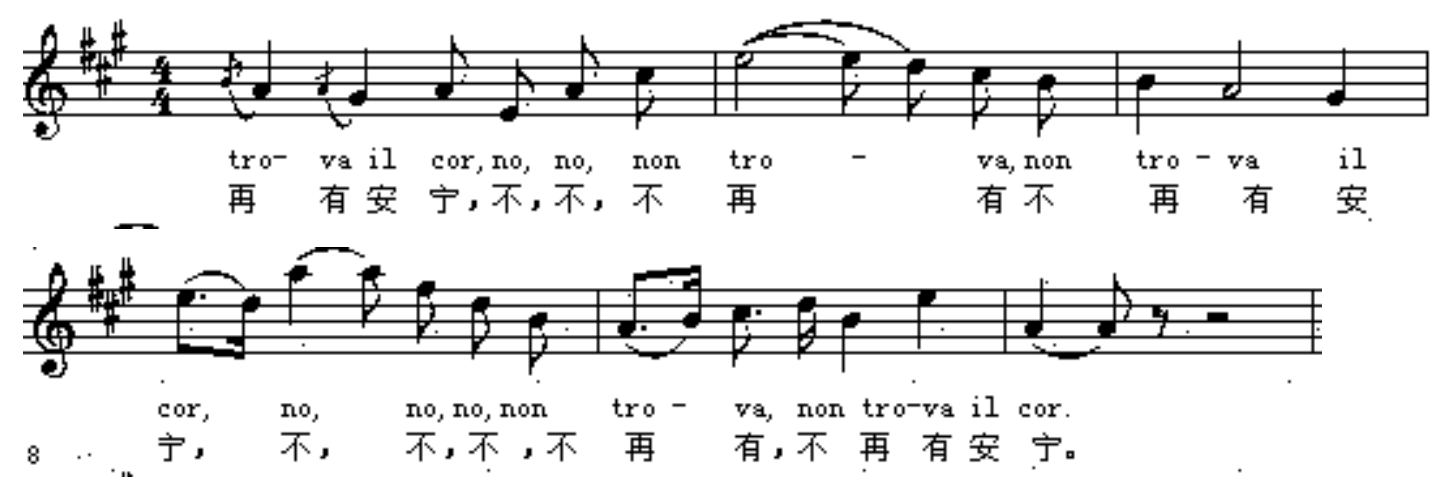

Spectral example No. 34 "Quando incise su quel marmo"

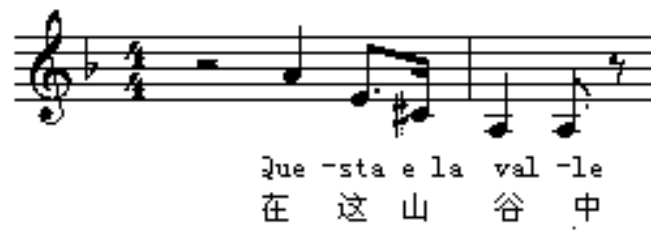

Spectral example No.35 "A palpitar daffanno"

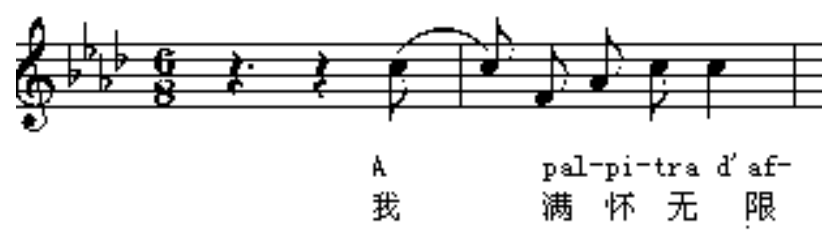

Spectral example No.36 "La farfalletta"

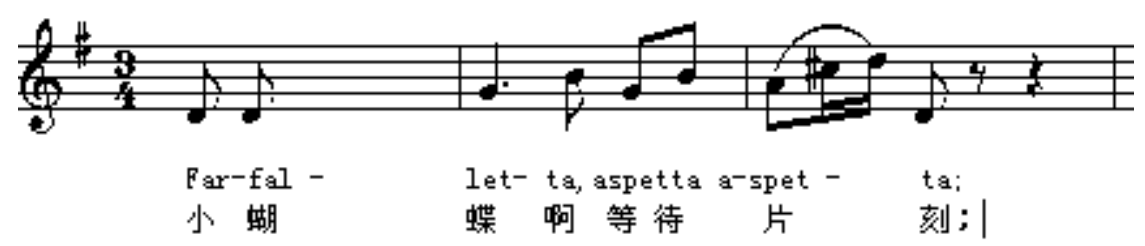

Spectral example No.37"Vanne o rosa fortunate"

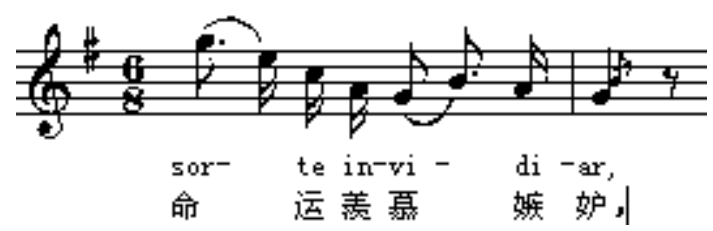




\section{E. Jump Interval Training}

The fifth, sixth, seventh, and eighth often appear in Bellini's art songs, and there are more sixth notes. Especially in the romantic music vocal works, the big jumps appear very frequently. Therefore, it is very important and meaningful to train the big jump interval for singing vocal romantic music works.
It is more scientific to take a step-by-step approach to the training of jumping intervals on the basis of progression training. Because the distance between the notes is increased, the adjustment of the degree or quantity of singing breathe will be relatively large, the degree of mouth opening condition needs to be adjusted in time. The unity of low positions of singing and breathing is very important and must be emphasized during training.

Spectral example No. 38 "Ma rendi pur contento"

Ascending 5 degrees jump into interval

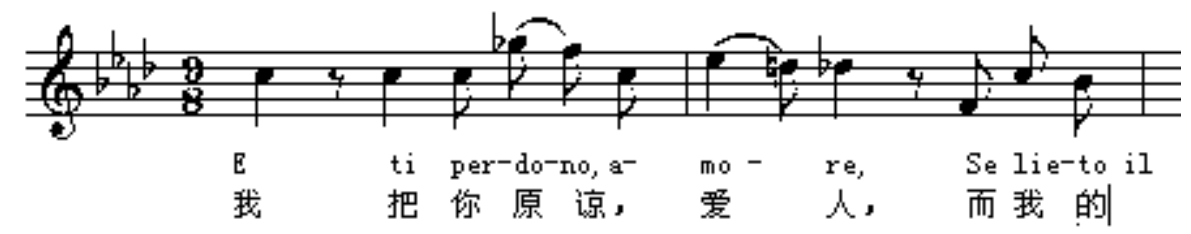

Spectral example "L’allegronarinaro"

Descending 5 degrees jump into interval

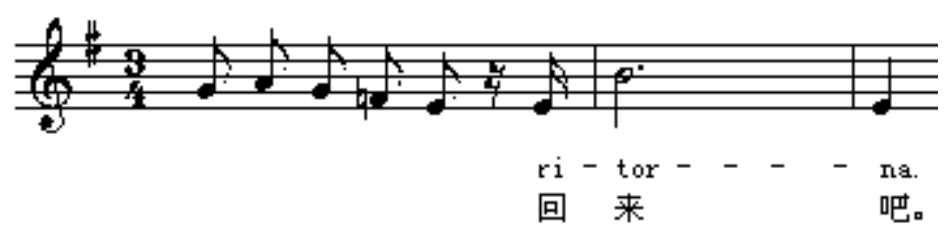

Spectral example No.39 "Per pieta bellidol mio"

Ascending 6 degrees jump into interval

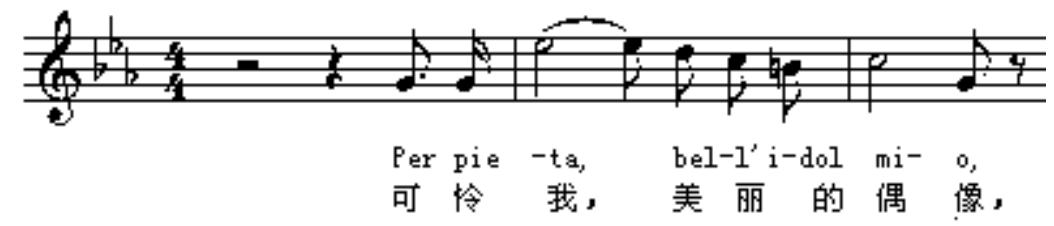

Spectral example No.40 "Almen senon poss lo"

Ascending 6 degrees jump into interval

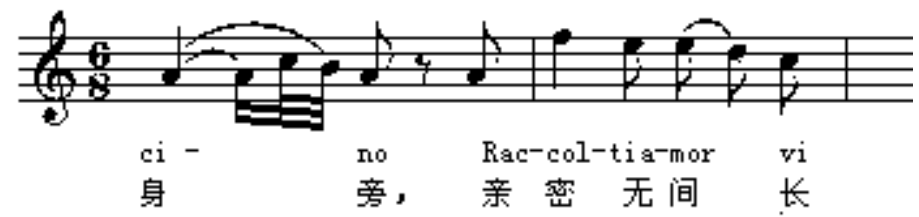

Spectral example No.41 "Malinconianinfa gentile"

Descending 6 degrees jump into interval

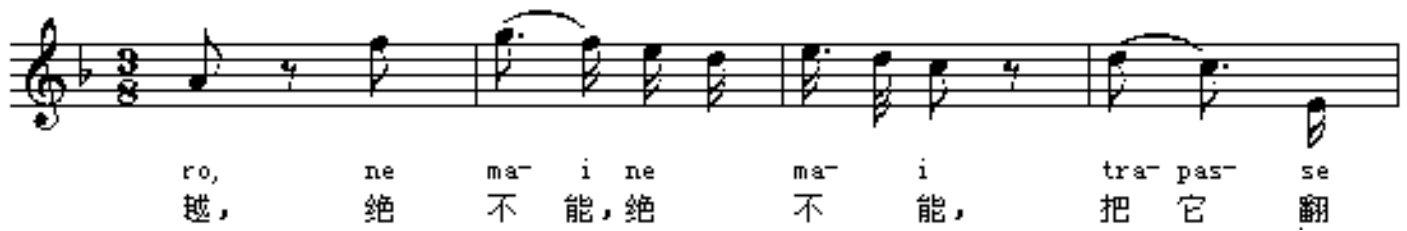




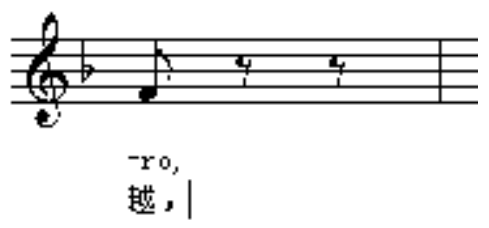

Spectral example No. 42 "Quando incise su quel marmo"

Ascending 7 degrees jump into interval

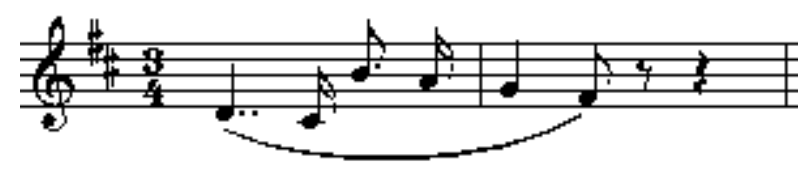

-dea di chi $t^{\prime} a-d o-r a$,
被 你爱恋 的人,

Spectral example No. 43 "Torna, vezzosa Fillide"

Ascending 7 degrees jump into interval

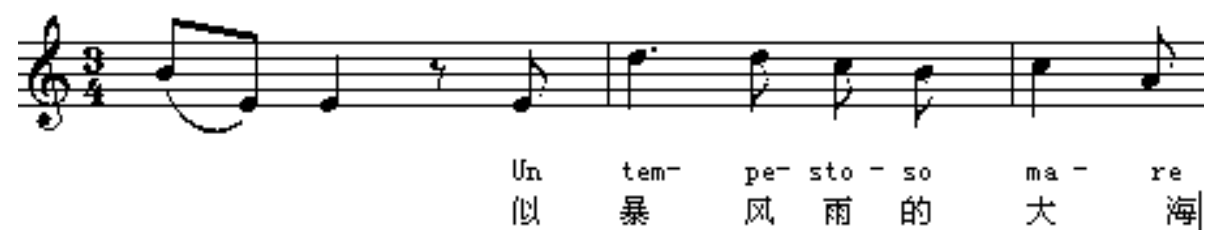

Spectral example "Torna, vezzosa Fillide"

Ascending 7 degrees jump into interval

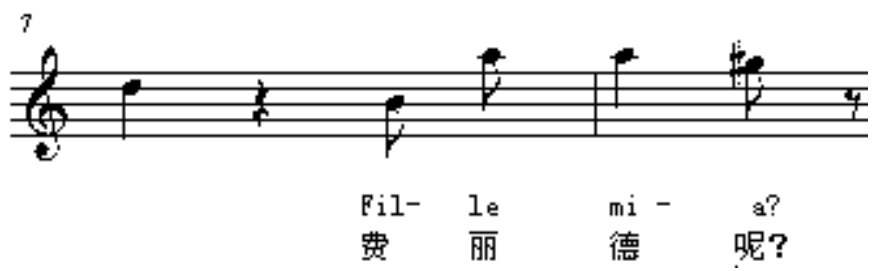

Spectral example No. 43"Sognod infanzia"

Descending 8 degrees jump into interval

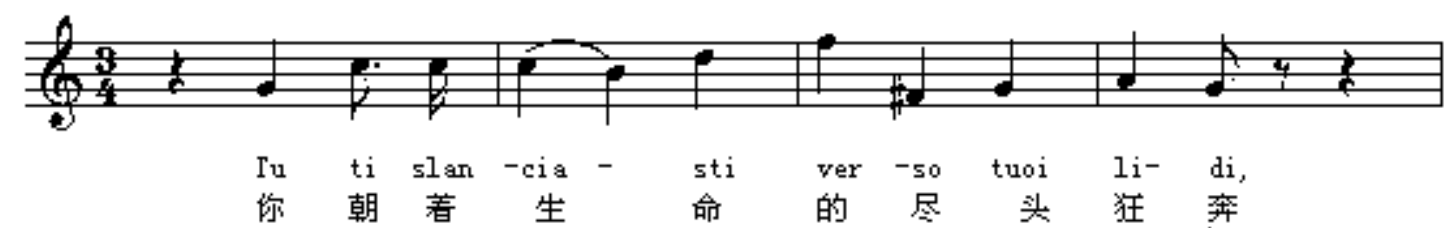

Spectral example "Quando incise su quel marmo"

Descending 8 degrees jump into interval

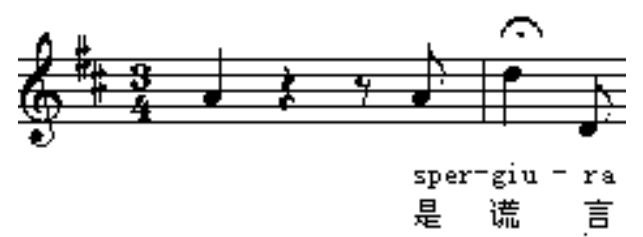

Spectral example "L’allegronarinaro" 
Ascending 8 degrees jump into the interval

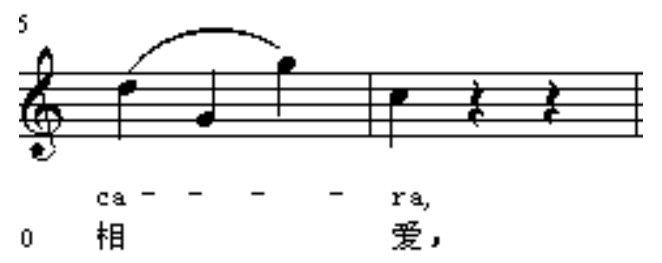

The greater the distance between the tones, the higher the singing state's enthusiasm will have to be adjusted. However, it is necessary to consciously keep the breath at the diaphragm position, and avoid by all means to lift the breath once get excitement. There is also the need to ensure the low position of the inhale state with low and high pitch consistent, which is the key of training. In this way, the vocalization channel will be unobstructed, and the treble will not appear to be crowded, blocked or hard. At the same time, it also trains the elasticity and tension of the vocal cords.

In the descending intervals, a very high tone is directly connected to a very low tone. Training to keep the positive

Spectral example No.44 "Malinconianinfa gentile" state of sing treble up to the state of singing bass can avoid loose breath and pressure throat.

\section{F. End Soundascending Big Jump Interval Training}

Some songs in Bellini's art songs often have an ascending jump interval in the ending of some phrases, which is a more difficult training. When the breath is almost running out, there is an ascending big jump interval, and the length of this high tone is relatively long. This is to test whether the singers have a long, broad and lasting breath support. It is also the training of breathe maintain and control ability.

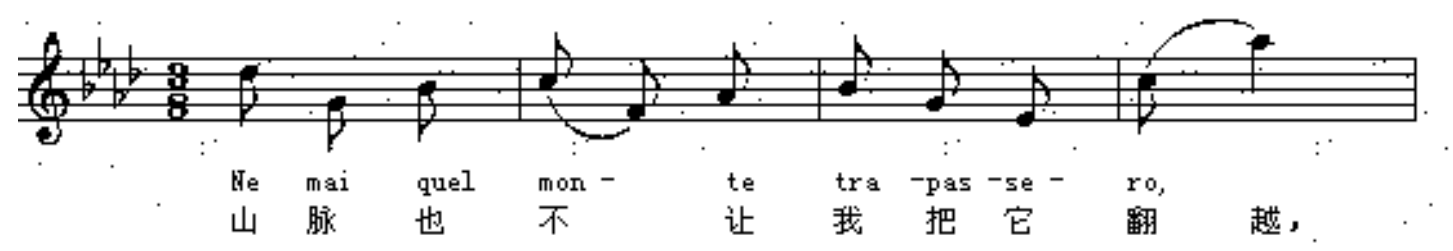

Spectral example No.45 "Almen senon poss lo"

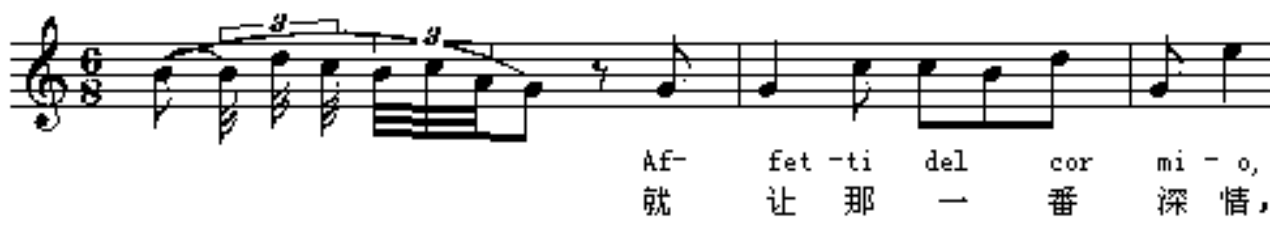

Spectral example No. 46 "O crudel che il mio pianto"

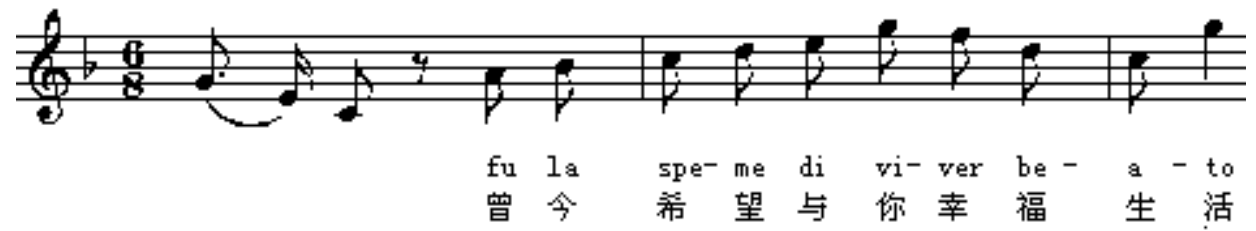

Spectral example "Torna, vezzosa Fillide"

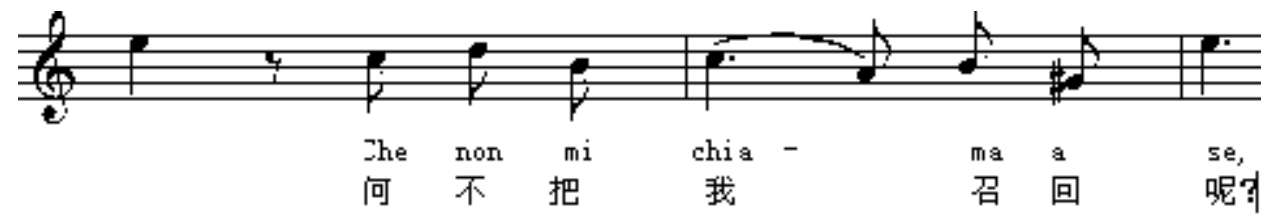


Spectral example "Sognod infanzia"

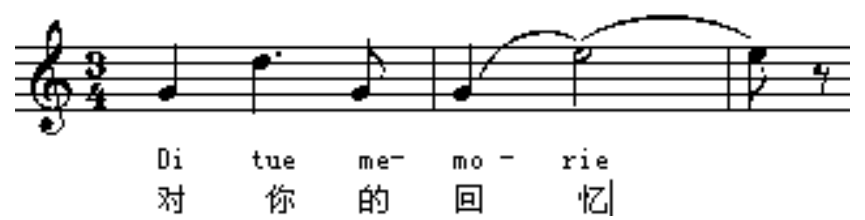

\section{G. Half-tone, Chromatic Tone Training}

Bellini's art songs have a lot of half-tones and chromatic tones, such as spectral example 36, 39, and 43 in the article. The practice of half-tones and chromatic tones can help to train the singer's singing pitch ability, and it can also help the learner to train the concept of a fixed singing spectrum.

Chinese musical styles do not have these frequently halftones and chromatic tones, especially the sound concepts and atmosphere of such changing half-tones and chromatic tones. Therefore, it is not easy to sing half-tones and chromatic tones accurately. By singing Bellini's art songs, you can train and improve the intonation ability and the ability to sing the fixedtone spectrum.

When some singers sing half-tones and chromatic tones, the tone color is very heavy, not clear, thus making the harmonic frequencies too slow and the sound too shake. Halftones and chromatic tones can not sing very accurately, and the sound appeared very cumbersome. Therefore, training halftones and chromatic tones can help the singers to have a more sensitive sense of range, and it can test and train whether the singer's singing voice is clear, clean, and light, whether their harmonic vibration frequency is balanced and natural.

\section{H. Training of Cabaletta's Rapid Coloratura}

Although Bellini's art songs are mainly performed smoothly, the melody lines of singing are prolonged and with ups and downs. And often at the end of the sentence, when the emotions reach a climax, there will be a rapid coloratura melody of cabaletta. From the aspect of vocal vocalization, this

Spectral example No. 46 "Seilmiononesapervoibranate" kind of cabaletta rapid coloratura is a singing melody with show off characteristics. However, for the composer's creation, this gorgeous coloratura writing is created based on the need of the song, so it revealed composer's true, natural and deep feelings. Therefore, when singing these rapid coloratura melodies in Bellini's art songs, the singers can not only show a dramatic exaggeration, but to sing it with seriousness, exquisiteness and excitement in order to respect the composer's original intention of creation, so that it can be truly infectious and shocking.

These rapid coloratura melodies in Bellini's art songs are the continuation of the style of rapid coloratura in the Baroque period, and are smooth melody in the second and third intervals. The singer's vocal state, mouth state, and breathing state are easy to be consistent, so that the singer's vocal function is very active, but it is also very relaxed and flexible, and the produced sound is consistent, smooth, mellow, flexible and lightweight, soft and with the same tone.

Usually these Cabaletta's rapid coloratura verses are long and difficult verses, so its singing skills are relatively difficult. Singing must be practiced in a steady vocal state and in an excellent singing mental state. Such melody training can be trained to the dexterity, continuity, patency, and mellowness of singing. At the same time, it is able to train the control and maintain the singing breathe so that the breath is even, long and broad, and has a good endurance. Through this training, the singer can sing longer and faster verses with a small amount of breath and strength, that is, singing with the minimum effort to achieve the maximum effect. This is one of the traditional half-tone singing techniques of Bel canto.

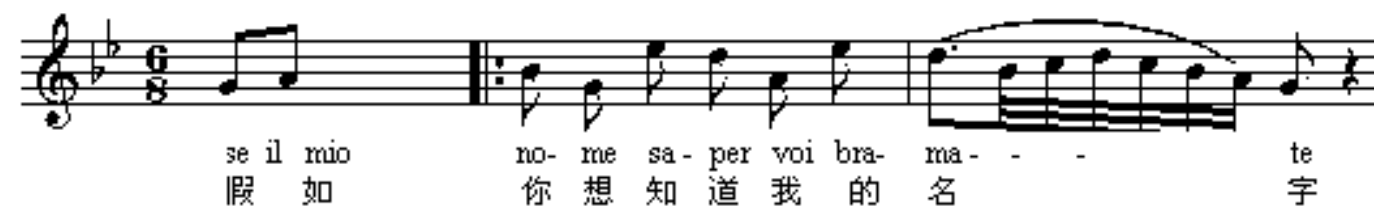

Spectral example No. 47 "Quando incise su quel marmo"

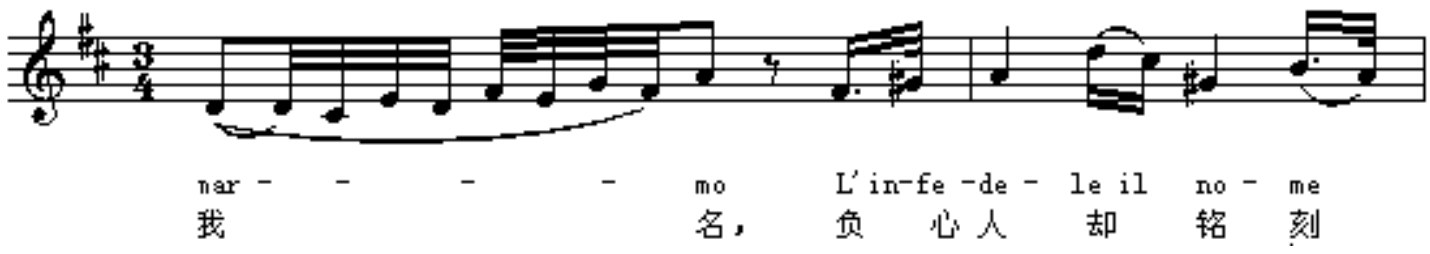



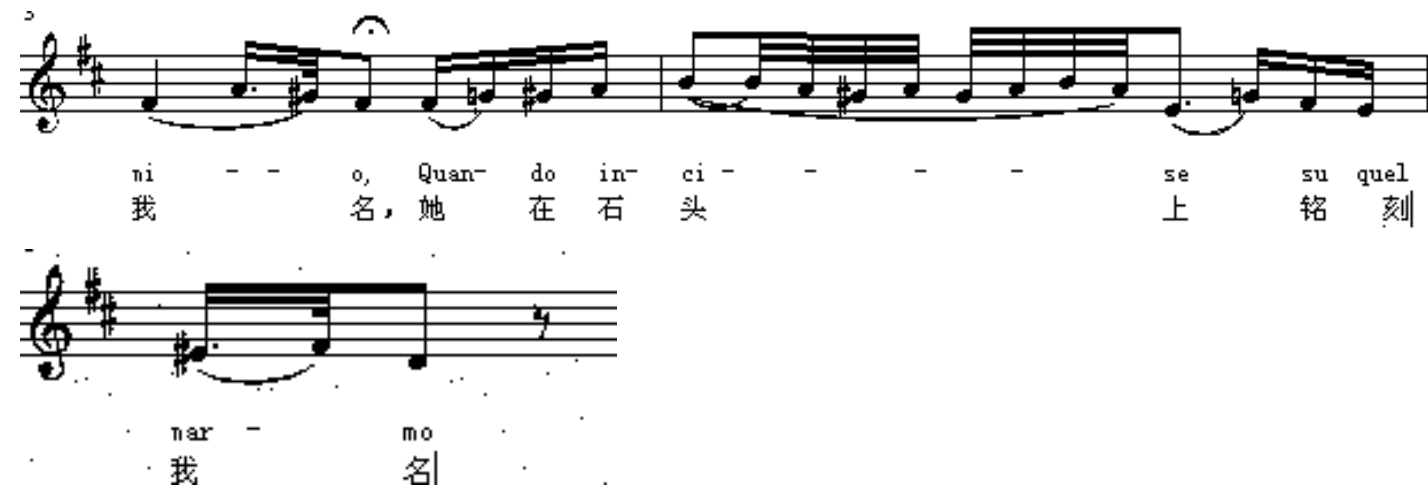

Spectral example No. 48 "IIfervidodesiderio"
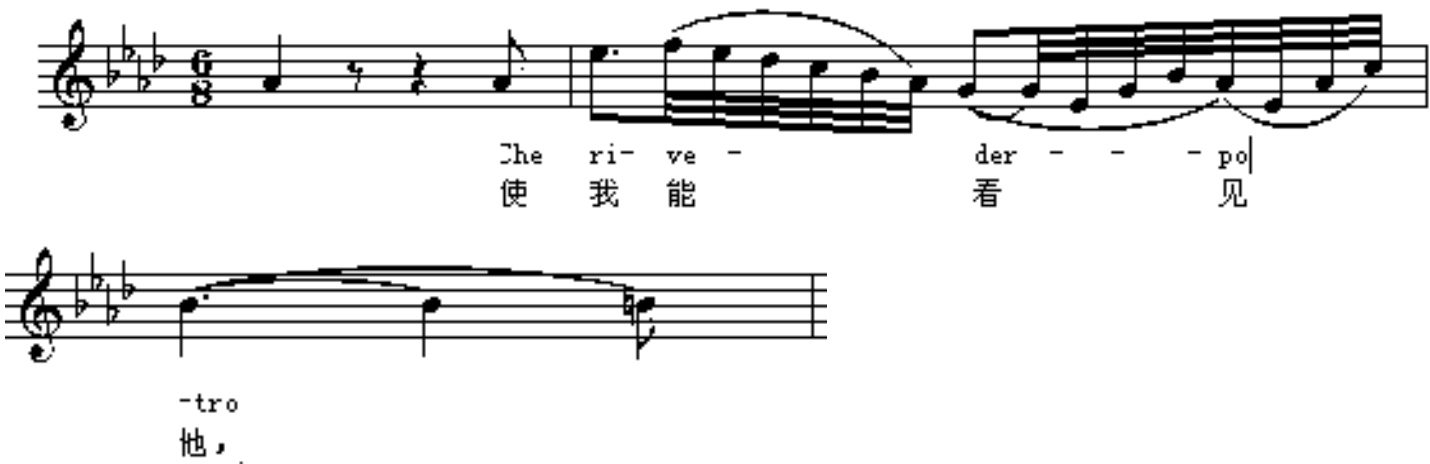

\section{Anadiplosis Melody Training}

Bellini's art songs often use anadiplosis creative techniques. The anadiplosis melody makes the connection between the verses close and natural, which makes the tune inexhaustible, euphemistic, and delicate.

When we sang, after the end of the first verse, and before the next verse we need to take a breath. Often the singer would take the initiative and eager to inhale, this kind of inhalation is natural, but it is not correct. Often the inhalation will absorb light and less air, which will affect the singing afterwards.

Spectral example No.49 "Fenesta ch lucive"
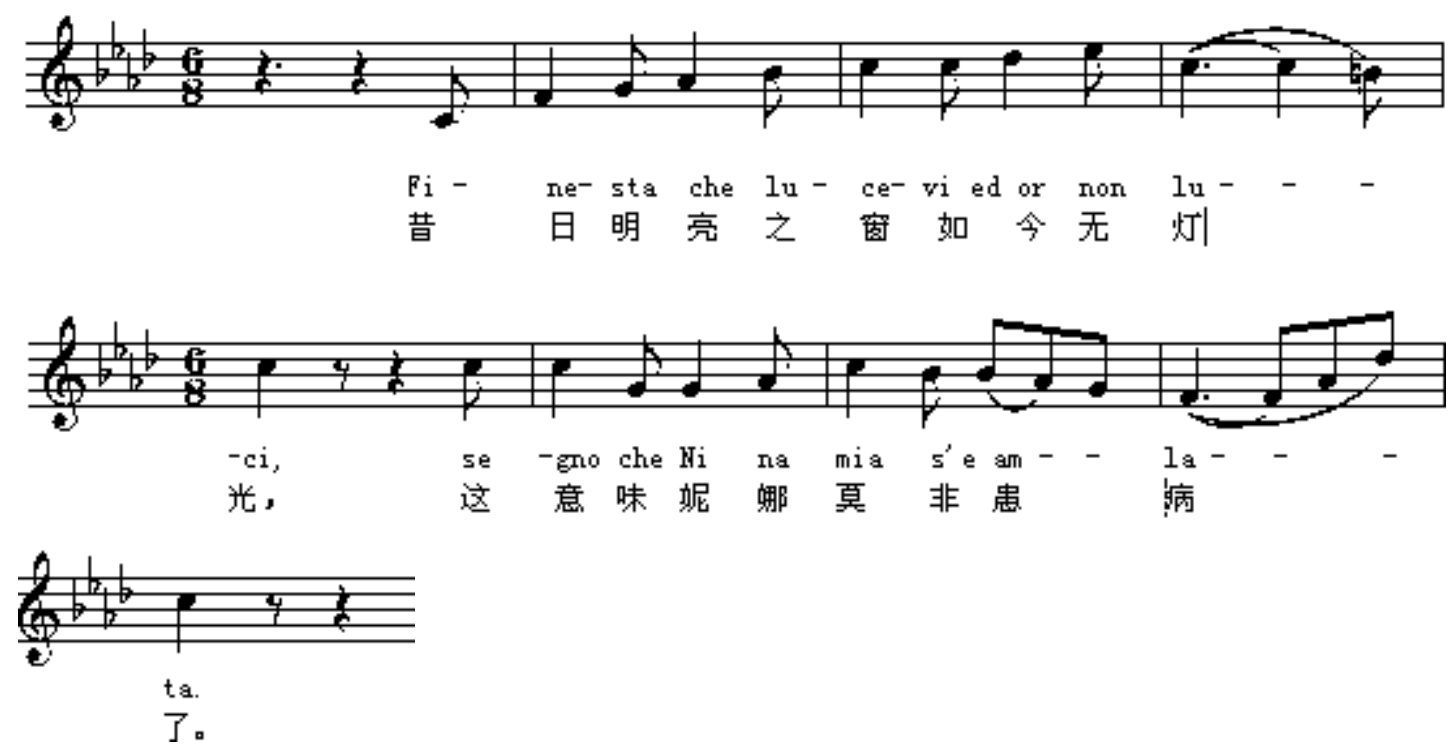

The characteristics of the anadiplosis melody determine that the ending tone of the previous verse is the same as the beginning tone of the next verse, so the state of singing and breathing is easy to keep consistent. When we take a breathe, as long as we keep and maintain the breathe state of ending tone, then the state of singing and vocalization will also be fine, so it will not affect the singing of the next verse. The effect of consolidating and stabilizing the vocal state of singing can be double. 
Spectral example No.50“Per pieta bellidol mio"
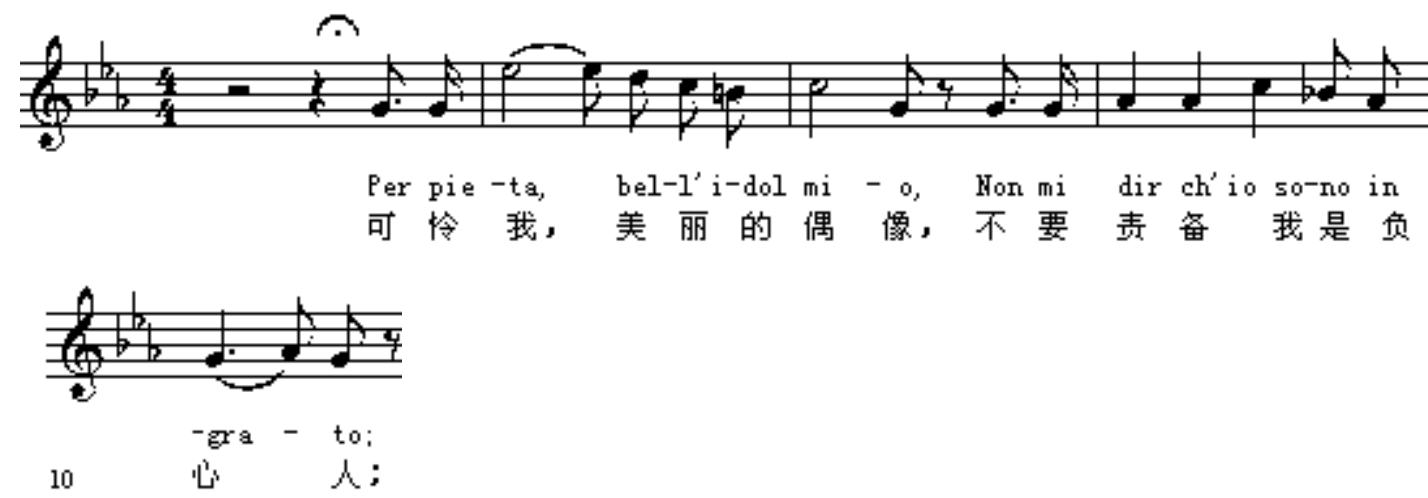

Spectral example No.51 "La farfalletta"
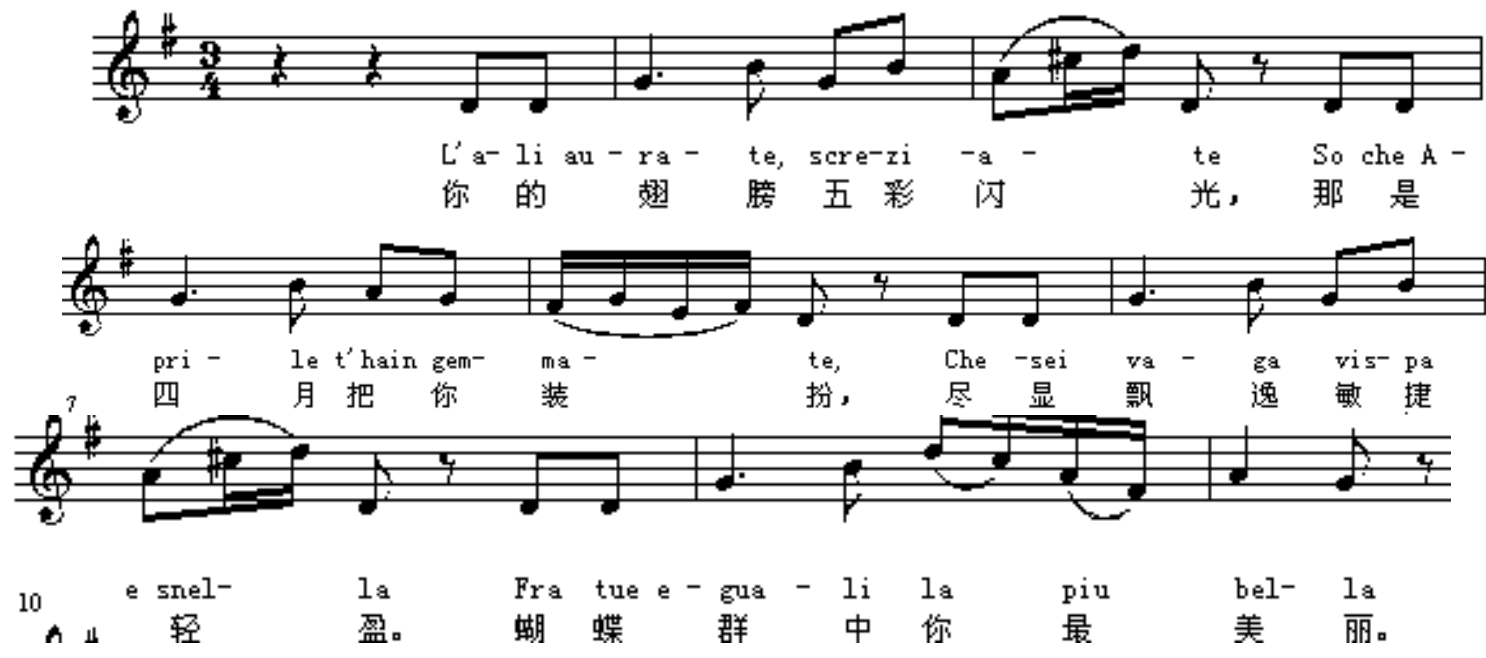

Spectral example No.52 "Torna, vezzosa Fillide"
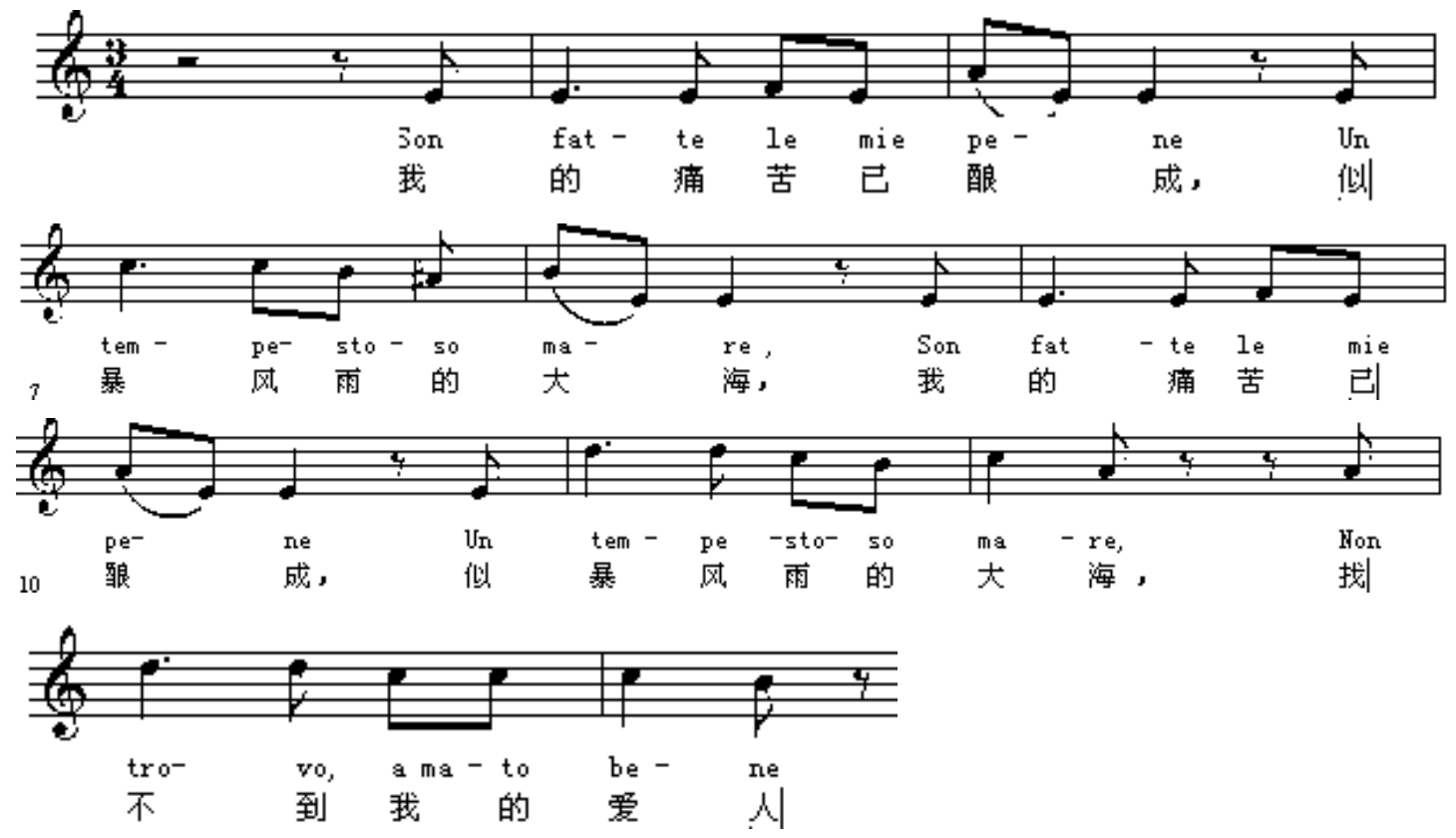


\section{J. Rondo Melody Training}

Bellini's art songs often have rondo melody. The rondo around a main tone, hovering back and forth. It is usually played in the upper and lower second intervals, forming a melodic form. The rondo melody can train the mellowness, dexterity, and twist of the sound. The upper and lower second intervals can make the vocal state easier to grasp, and it is not easy to change the vocal state of singing, including breath, oral cavity, singing channel, etc., to maintain a certain state. So the produced sound is the same, and also makes the singing sound normal and open.

Spectral example No.53 “L'abbadono"

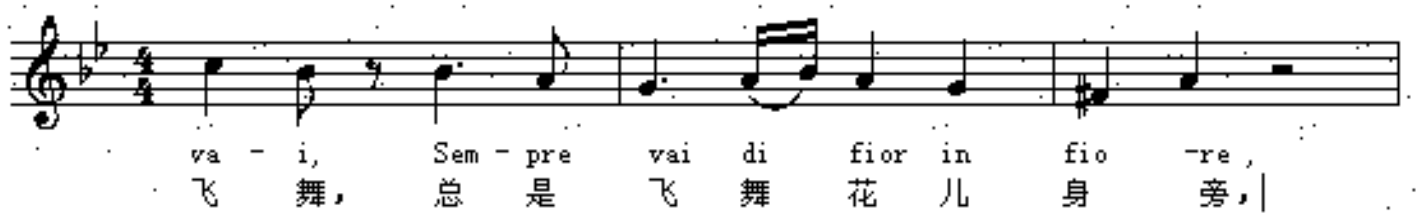

6 (la) is the primary note in the spectrum, other notes are performed around the upper and lower two degree intervals.

Spectral example No.54 "Torna, vezzosa Fillide"

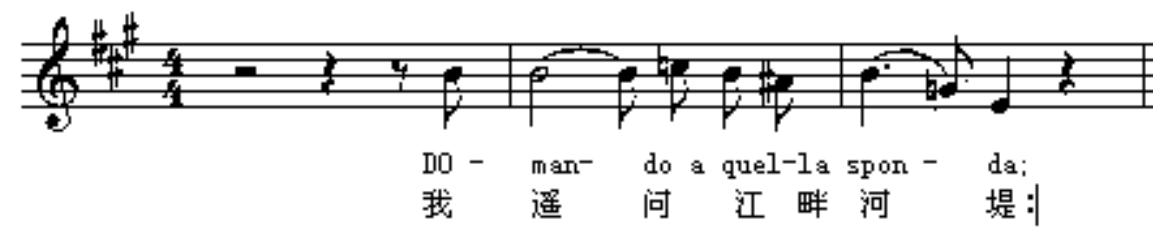

7 (si) is the primary note in the spectrum, other notes are performed around the upper and lower two or three degree intervals.

Spectral example No.55 "Torna, vezzosa Fillide"

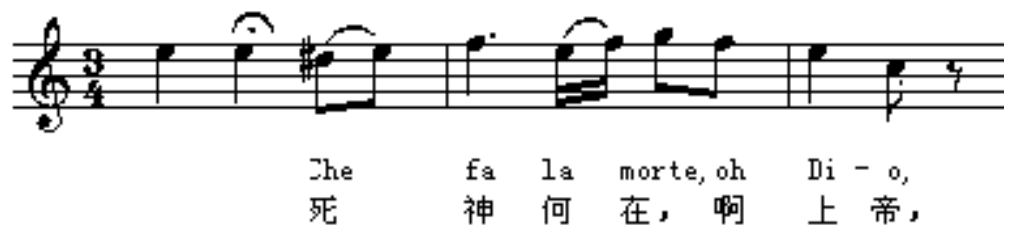

4 (fa) is the primary note in the spectrum, other notes are performed around the upper and lower two degree intervals.

Spectral example "Torna, vezzosa Fillide"

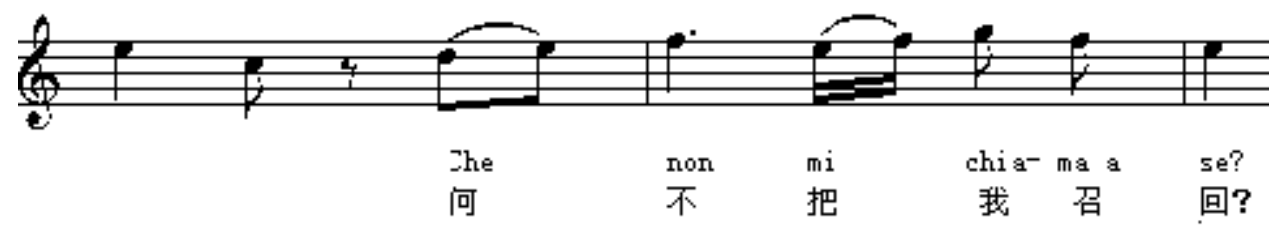

Spectral example No.56 "Seilmiononesapervoibranate"

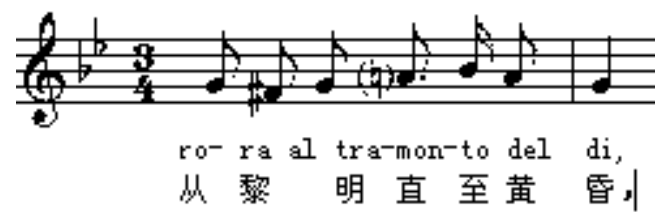

5 (so) is the primary note in the spectrum, other notes are performed around the upper and lower two degree intervals.

Spectral example "L’allegronarinaro" 


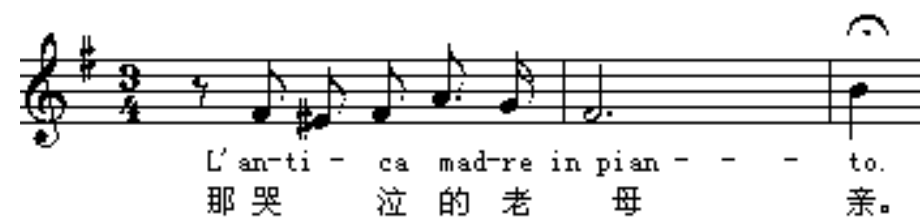

4 (fa) is the primary note in the spectrum, other notes are performed around the upper and lower two or threedegree intervals.

Spectral example "Sognod infanzia"

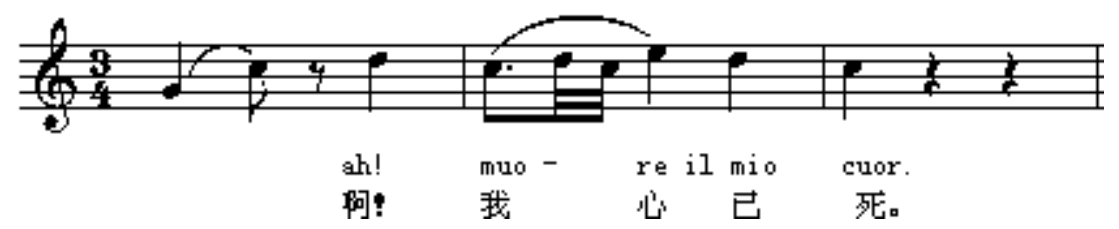

1 (do) and 2 (re) can both consider as the primary note, they are performed around the upper and lower two or three degree intervals

\section{K. One Word for One Tone or Multi Word for One Tone Training}

In Bellini's art songs, the mix of singing melody and lyrics is basically in the form of one word for one tone or multi word for one tone, so that it is easier to train the singing language. Since these lyrics are all Italian, the language help the most singing, and then to promote the efficiency of singing voice training.

One of the most important benefits of one word for one tone or multi word for one tone singing is that it could make the singing mouth not easy to become stiff and nervous due to keeping the same opening and closing state for a long time, which affects the correctness of the vocalization function. The one word for one tone or multi word for one tone singing can make the gesture of biting frequently, and the singing is easy to be clear and accurate, so the timbre of vocalization is also bright and shiny, which could make the singing voice last forever. In addition, the frequent action of biting makes the work function of the oral cavity more relaxed and natural, so singing becomes easy and flexible, and it will not make muddy, unclear, and backward sounds. This is also a good training method for solving vocal problems such as timbre turbidity, voice shaking, and inarticulate singing.

\section{Restrained and Extroverted Singing Emotional Expression Training}

In the analysis and discussion of the previous article, the author has already explained the melody of Bellini's art songs is mainly based on the second degree progression. This kind of melody is more soothing, elegant, natural without exaggeration, exquisite and profound. Even the rapid coloratura at the vocalization part must should respect the original intention of the composer Bellini, and sing inwardly to express the true and natural emotions. This requires the singer to really study the connotation of the song in earnest, understand the plain and sincere thoughts and feelings of Bellini's creations, and devote himself to the artistic conception of the song, which expresses the sad and bitter tragedy in Bellini's songs. For those cheerful songs, the sad and lyrical song can infect more people and inspire people's thinking. Therefore, the expression of emotions will have deeper meaning.

On the other hand, Bellini also used some of his skilled opera writing techniques in his art songs, with obvious characteristics of operatic dramatic conflicts, beautiful and coherent aria features, and natural lyrical narration features, which have been analyzed in the previous article. When singing these paragraphs with dramatic features, it is necessary to draw on some of the emotional expressions that are shown in the opera singing and extroverted to highlight the dramatic conflict of the singing mood and make a sharp contrast between the emotions before and after. Therefore, at that time, the singer must positively and emotionally declare the emotions of the song from the inside out, so that the expression of the singing can be more profound and moving.

In the long time last training, constantly experiencing and practicing the expression of restrained and extroverted emotions will make the singer's handling of singing emotions more mature, more profound, more infectious and deterrent. This is also the cultivation of singing art.

\section{CONCLUSION}

Bellini, a famous opera composer in the Romantic period of the first half of 19th century, used his short life he wrote a very charming and very unique musical melody, left us a precious musical legacy for us. Under the wide influence of his opera arias, it also stimulated people to learn, sing and study his art songs, thus discovering the precious value of Bellini's art songs.

Bellini expresses his thoughts and feelings with his special and unique musical language. Only by carefully studying and analyzing Bellini's unique and personalized musical style, can we understand and excavate the value of his art songs, and then we can truly understand the meaning of his music while respecting the original intention of his creation and helping guide our singing, teaching, developing our singing skills and teaching standards. 


\section{REFERENCES}

[1] Jia Tao. Translation: "Collection of Bellini's Art Songs", Central Conservatory of Music Press, 2008

[2] Zhou Tongfang Translation: "Bellini Art Collection", Music spectrum Publishing Company, Republic of China 88th years

[3] Yu Yixuan Selection: "Selection of Rossini Donizetti Bellini's Art Songs", People's Music Press, 2007

[4] Shen Xuan, Gu Wenxian: "Compendium of Western Music History", Shanghai Music Publishing Company, 1999

[5] Li Weibo: "Introduction to Western Vocal Music Development", World Book Press, 1999

[6] Guan Jinyi: "Critical Review of European Famous Musicians”, Beiyue Literature and Art Publishing Company, 2000

[7] Liu Congxin, Liu Zhengfu, "The History of European Vocal Music", China Youth Press, 1999

[8] Zhang Hongdao, Editor-in-Chief: "History of European Music", People's Music Publishing Company, 2001

[9] Yu Dugang, Wang Dayan: “ Introduction to Art Songs”, Shanghai Music Publishing Company, 2009

[10] Zou Changhai: "Art Psychology of Vocal Music", People's Music Publishing Company, 2000

[11] Li Xiujun: "Analysis and appreciation of Western Romantic Music", Shanghai Music Publishing Company,2008

[12] Shanghai Institute of music research, Wang Qizhang, Gu Lianli, Wu Peihua translation: "Foreign music vocabulary", Shanghai Music Publishing Company, 1988

[13] Li Jinwei, Li Jinyuan: "The art of Shenxiang Vocal Education", Huayue Publishing Company, 2003

[14] Zhao Meibo: "Singing Art", Shanghai Music Publishing Company, 1997

[15] Lin Yicong: "Music Bible”, Huaxia Publishing Company, 1999

[16] Chen Lihan: "An Analysis of Bellini's Art Songs", Popular Literature, 2010

[17] Tao Tao: "The Value of Bellini's Art Songs", Yi Hai, 2009

[18] Wang Qin: "Study on Bellini's Creation of Art Songs", Voice of Yellow River, 2011

[19] Zang Wan: "Study on Bellini's Song Creation from'Vaga luna che inargenti'", Popular Literature, 2010

[20] Jiang Fang: "A Study of Bellini's Opera Soprano Aria”, Shanghai Conservatory of Music, 2007 